WINTER, Agnes, Das Gelehrtenschulwesen der Residenzstadt Berlin in der Zeit von Konfessionnalisierung, Pietismus und Frühaufklärung (1574-1740)

Michel Espagne

\title{
OpenEdition
}

Journals

Édition électronique

URL : http://journals.openedition.org/ifha/1851

DOI : $10.4000 /$ ifha. 1851

ISSN : 2198-8943

Éditeur

IFRA - Institut franco-allemand (sciences historiques et sociales)

Référence électronique

Michel Espagne, «WINTER, Agnes, Das Gelehrtenschulwesen der Residenzstadt Berlin in der Zeit von Konfessionnalisierung, Pietismus und Frühaufklärung (1574-1740) », Revue de l'IFHA [En ligne], Date de recension, mis en ligne le 01 janvier 2009, consulté le 22 septembre 2020. URL : http:// journals.openedition.org/ifha/1851; DOI : https://doi.org/10.4000/ifha.1851

Ce document a été généré automatiquement le 22 septembre 2020.

(C)IFHA 


\title{
WINTER, Agnes, Das
}

\section{Gelehrtenschulwesen der Residenzstadt} Berlin in der Zeit von Konfessionnalisierung, Pietismus und Frühaufklärung (1574-1740)

\author{
Michel Espagne
}

En se fondant sur une analyse systématique des archives des lycées berlinois, des sources manuscrites et imprimées illustrant leur devenir, et en croisant la description de ces établissements durant deux siècles d'histoire avec les transformations de la Prusse pendant la même période, A.W. fournit une contribution de tout premier plan à l'histoire de l'éducation en Allemagne. Le cadre dans lequel l'auteur situe son propos est celui d'une Prusse où se constitue une Église luthérienne, mais où le passage à la Réforme calviniste entraîne une diversification des pratiques sociales, la tension entre les états luthériens et la cour calviniste favorisant l'émergence d'une élite politique relativement indépendante des états et entièrement dévouée au prince. La présence de 6000 Français à Berlin vers 1700 sur une population globale de 25000 personnes contribua, comme l'émergence du piétisme sous l'influence de Philipp Jacob Spener, à soumettre à une forte pression l'Église luthérienne dominante. Pufendorf, Spener et Leibniz annoncent le début des premières Lumières qui s'établissent à l'Université de Halle, créant un conflit avec le piétisme dont témoignent les destins de Thomasius et surtout de Wolff. C'est dans ce cadre général que les écoles berlinoises, s'adressant aussi bien aux classes bourgeoises qu'à la noblesse, assument un rôle central dans les dynamiques de confessionnalisation et de territorialisation, puisqu'elles vont former les pasteurs et les fonctionnaires dont le pays à besoin. Elles vont être soumises à des degrés divers tant à l'autorité du sénat de Berlin qu'à celle du prince-électeur. Le premier établissement mentionné est le lycée "Zum Grauen Kloster » dont l'ouvrage décrit le mode de fonctionnement et les fondements économiques. Puis viennent le lycée de Cölln, le gymnase de Joachimsthal, conçu comme un internat princier, où la 
nomination des enseignants fit l'objet de tensions entre les calvinistes de la cour et l'Église luthérienne. L'influence des prédicateurs de la cour dans la gestion de ce dernier lycée se marque notamment dans la constitution d'un directoire chargé d'assumer la direction de l'établissement. Fondé en 1681, le lycée de Friedrichswerda fut, lui, clairement biconfessionnel. Enfin le collège français, sur lequel les archives sont très lacunaires, date de 1689 , et ses deux premiers professeurs de philosophie, Jean Sperlette et Étienne Chauvin, en firent un point de cristallisation des premières Lumières. La prosopographie des enseignants de ces divers établissements, même si elle n'aboutit pas toujours à recenser des personnalités de premier plan comme celle du piétiste Joachim Lange au Friedrichswerder Gymnasium, constitue un apport important à l'histoire de la vie intellectuelle à Berlin, et cela d'autant plus qu'A.W. entre dans le détail des programmes d'enseignement de chacun des établissements, énumérant les manuels utilisés, observant le poids relatif du latin et du grec ou de nouvelles disciplines. Des tableaux précisent les origines géographiques ou universitaires des enseignants et signalent la suite de leur devenir professionnel. La même enquête sociologique est conduite pour les élèves. Ceux-ci sont divisés en classes de niveau plutôt que d'âge et n'entrent pas dans les lycées de Berlin avant 12 ou 13 ans. À 1 'époque du Grand Électeur, ils ne fournissent pas encore l'essentiel des fonctionnaires de la cour, mais vont, durant toute la période, contribuer à la vie musicale. Les auteurs de poésies de circonstance se recruteront dans leurs rangs, et dans ceux de leurs enseignants, qui vont constituer les piliers d'une république des savants, s'exprimant notamment dans la Revue germanique ou dans le Nouveau journal des savants. On dispose désormais d'une cartographie très précise de l'enseignement berlinois, de ses conditions économiques et de ses contenus pédagogiques permettant de dire quand et où l'apprentissage du grec a eu une importance, quand et où la pensée de Melanchthon a commencé à être relayée par les modèles intellectuels de Wolff, quand et où un premier enseignement de l'histoire a complété celui des artes dicendi. Le livre d'A.W. constitue, pour les historiens de la vie intellectuelle à Berlin, un ouvrage de référence.

Michel ESPAGNE (Centre National de la Recherche Scientifique) 